\title{
Systemic Lupus International Collaborating Clinics/American College of Rheumatology-Damage Index
}

National Cancer Institute

\section{Source}

National Cancer Institute. Systemic Lupus International Collaborating Clinics/American

College of Rheumatology-Damage Index. NCI Thesaurus. Code C121353.

A clinical index used to measure accumulated org an damage from either the disease process or its sequelae, in twelve organ systems. The index scores damage regardless of cause. The definition of damage is an irreversible change in an organ or system that has occurred since the onset of systemic lupus erythematosus and is present for at least six months. 